\title{
Investigating Relationship of Perceived Learning Engagement, Motivation, and Academic Performance Among Nursing Students: A Multisite Study
}

\author{
Hala Mohamed Mohamed \\ Bayoumy (D) ' \\ Sharifa Alsayed iD ${ }^{2}$ \\ 'Department of Nursing, Cairo \\ University, Giza, Egypt; ${ }^{2}$ College of \\ Nursing, King Saud bin Abdulaziz \\ University for Health Sciences, Jeddah, \\ Saudi Arabia
}

Background: Learning engagement, motivation and academic achievement are vital growing areas in academic research. Evidence suggests that students' engagement and motivation are positively linked to improved quality of learning. However, limited number of research studies have been conducted within this scope. Therefore, the present study was conducted to investigate the relationship of learning engagement, motivation and academic performance among university nursing students.

Participants and Methods: A descriptive design, with a comparative correlational approach for data analysis, was used to describe and compare study outcomes. Data was collected from 425 students at King Saud bin Abdul-Aziz University for Health Sciences campuses in Riyadh, Jeddah and Alhasa. Study instruments included background data sheet, students' engagement in schools (SESQ-ENG), engagement facilitators (SEI), academic motivation (AMS), and academic achievement as measured by cumulative and last semester grade point average (cGPA, sGPA).

Results: Overall, level of engagement was moderate (mean $=3.70 \pm 0.63$ ) with significant differences among campuses $(\mathrm{F}=18.88, \mathrm{p} \leq 001)$. Students' perceptions of engagement facilitators and academic motivation were high (mean $=2.98 \pm 0.49,4.89 \pm 1.03$, respectively), and both varied by campus $(\mathrm{F}=6.35, \mathrm{p}=0.002, \mathrm{~F}=9.85, \mathrm{p} \leq .001$, respectively). Engagement, motivation, and academic achievement showed medium to large correlations (i.e., between 0.20 and 0.63). Multiple regression equation including age, academic progress, academic engagement, motivation and engagement facilitators significantly explained $24 \%$ of variance in cGPA (F ( 5 , $226)=14.209, \mathrm{p}<0.001)$ and $22 \%$ of the variance in $\operatorname{sGPA}(\mathrm{F}(5,214)=12.202, \mathrm{p}<0.001)$. Conclusion: This study showed significant associations of students' engagement, facilitating conditions (e.g., engagement-fostering aspects), and students' motivation with significant effect on academic achievement. It is hoped that findings of this study could be used as quality indicators to direct school efforts towards achieving excellence in nursing education.

Keywords: nursing, students' engagement, motivation, academic achievement

\section{Background}

Educational experiences are only as effective as students' engagement with them; because it is students who choose how effortful to engage in the learning process and, certainly learn. Crookes, Crookes and Walsh (2013) ${ }^{1}$ stated that nursing educators are often urged to make the theoretical material they cover meaningful and engaging in a way that enables students to establish a link between the content
Correspondence: Hala Mohamed

Mohamed Bayoumy

Tel +20 I555293519

Email hamr77@hotmail.com 
of the course and its practical application. Students who engage efficiently in their learning will not only be beating toward their academic success, but will also be confident problem solver, self-assured, forthright and resilient when facing future responsibility for heightened levels of patient care. $^{2,3}$ Student's engagement and motivation are considered effective learning component for improving the quality of nursing education. ${ }^{4}$

Thus the purpose of this multisite study was to examine the association of nursing students' engagement with motivation for leaning and the relative roles of these two factors in predicting academic performance outcome among nursing students. The study, therefore, has focused on different conceptually distinct aspects of engagement: behavioral, emotional, and cognitive. ${ }^{5}$ These are welldefined, highly studied, areas that represent the range of educationally important engagement constructs. ${ }^{5-7}$ Efforts are also directed towards clarifying not only indicators of students' engagement but also some specific engagement facilitating conditions (e.g., engagement-fostering aspects of the classroom environment, students' motivation). Contextual variables that influence students' engagement and motivation are complex and uncertain, therefore the study also seeks to answer the question of whether the characteristics of students have any impact on studied outcomes.

This article is significant as there is a lack of knowledge as regards to Saudi nursing students' engagement levels and motivations in the local research. It is hoped that the findings of the current study are used as a quality indicator to direct existing efforts in renovating nursing programs and the achievement of excellence in nursing education.

\section{Literature Review}

Academic success is one of the most widely studied outcomes in educational research and assessment. Nursing education is a substantial personal investment of time and efforts for the student and a major investment of governmental in many countries, it is therefore important to support students' success in their academic education. Equally important is the need to identify predictors of academic success to ensure quality education and high completion rates.

Mthimunye and Daniels $(2020)^{8}$ defined successful academic performance as the student's achievement of the college minimum academic prerequisites to effectively and successfully complete a module or year of study. York,
Gibson and Rankin (2015) $)^{9}$ indicated that grades and particularly college grade point average (GPA) being the most convenient and readily accessible assessments, are the ultimate widely used measure of academic achievement that captures the quality of students' academic achievement. Truly, York, Gibson and Rankin (2015) ${ }^{9}$ contend that studies concerned with the identification of various conditions that facilitate academic performance are proliferating. In different circumstances of both the online learning and traditional classroom settings, various complex factors affecting academic performance have been considered among nursing students. Moreover, conditions studied are numerous, among which are standards for academic learning, meaningful and engaging instruction, learning environments and motivation.

Learning engagement and its association to academic performance is one of the latest rising fields of academic research that seeks to enhance the quality of learning for students. Engagement has been widely recognized as an essential component of nursing education with an important influence on academic achievement and learning among university students. ${ }^{10-12}$ Theorists conceptualize engagement as a multidimensional construct. ${ }^{6}$ The contemporary construct of engagement includes behavioural, emotional and cognitive dimensions. Behavioral engagement comprises academic and social participation, emotional engagement involves both positive and negative interaction with instructors, students, educators and schools, while cognitive engagement draws on idea of investment, integrates thoughtfulness and willingness to comprehend complex ideas and acquiring difficult skills. ${ }^{13}$ Based on the literature, the concept of learning engagement describes "the level of students' active involvement in classroom learning activities or other different learning activities." ${ }^{, 7}$ Generally, Exetera et al $(2010)^{14}$ reported that student engagement refers to the amount of time, energy and resources expended on activities designed to enhance university learning.

It is widely assumed that higher rates of engagement provide more knowledge and deeper understanding which, in effect, would prepare for graduates who are capable of providing higher standards of care. ${ }^{4}$ Moreover, institutions that engage their students entirely shall be deemed of higher quality. The level of commitment of a nursing student has a crucial impact on their learning, experiences in clinical care and, eventually, continuing success within the nursing profession. Engagement can assist shaping students into more independent thinkers and creative 
problem solvers, which could promote their necessary career transition. ${ }^{13}$ Exetera et al $(2010)^{14}$ explained that "engaged" student is one who strives to improve his/her knowledge, focuses on the facts and details related to their own experiences. In fact, evidence shows that student's engagement during college is positively associated with post-graduation labor market earnings. ${ }^{15}$ Student education must therefore facilitate engagement by being relevant and evidence-based. ${ }^{13}$

Knowing that, engagement is a vital component of the nursing education, the teacher who aims to create an active learning environment should encourage students to be active during class and encourage critical thinking activities. In addition, instructors can maintain student's engagement level by delivering various topics is extremely challenging to these groups. The learning style and teaching modalities employed seem to provide the learners with incentive to stay engaged with their learning. ${ }^{16}$ Since some students learn best through hearing and others through doing, so a variety of teaching methods is needed to facilitate learning. ${ }^{17}$

Teaching modalities that promote active learning styles can lead to greater engagement and learning. ${ }^{18}$ Cooper and Carter (2012) ${ }^{18}$ however identified few problems with this style of learning as student' reported issue of "not being able to know what the most important things were," and "not knowing if they studied the right thing." The challenges of these various delivery systems can be minimized with close monitoring, more reflective practice and timely guidance during student learning. It is worth noting that nursing students should be educated and empowered within a dual role, both in the school environment and in the clinical training sites. Students active engagement in both the academic and clinical hemisphere are essential for ensuring quality education with effective, current, and knowledgeable graduates. ${ }^{13}$ Crookes et al (2013) ${ }^{1}$ emphasized that nursing educators are often forced to develop theoretical material that are meaningful and engaging so that students are able to easily figure the connection between theoretical course content and its application in a clinical setting.

Disengagement found as a leading cause of major educational problems among learners, including boredom, increased dropout rates, and unsatisfactory achievement. ${ }^{19,20} \mathrm{Li}$ and Lerner $(2013)^{21}$ indicated that academic engagement has a significant role affecting student characteristics and their success. Dotterer and Lowe $(2011)^{22}$ found that engagement is a significant mediator between academic outcomes and classroom context. Mthimunye and Daniels $(2020)^{8}$ in a qualitative study exploring the challenges and efforts implemented to improve the academic performance and success among 50 university nursing students, their findings revealed that nursing students resort to active academic engagement as one of main approaches to face challenges hindering their academic achievement including inadequate academic and clinical support, and unfavourable physical educational environment. Casuso-Holgado et al $(2013)^{23}$ examined associations between engagement and achievement and found that GPA seems to be the variable most associated with engagement dimensions which explained between $18.9 \%$ and $23.9 \%$ of the variance in academic achievement $(\mathrm{p}<0.05)$ among university students.

On the contrary, Abdul Sattar, Kouar and Gillani $(2018)^{24}$ in a cross sectional study among 135 undergraduate students reported no significant relationship between student engagement and self-reported cumulative GPA. Abdul Sattar et al $(2018)^{24}$ study favored that student who hold low GPA try to engage more in their learning environment to get better results in future. On same vein, Ghiyasvandian, Shahsavari, Kazemnejad, Goodarzi and Razavi (2019) ${ }^{25}$ found that there was also a significant, but weak, relationship between the engagement to learning and academic achievement in the interactive classroom management. On same line, Abid and Akhtar $(2020)^{26}$ in a quantitative correlational investigation inspected the relationship of academic engagement and achievement of randomly chosen 800 of tenth grade students from 20 secondary schools, their outcomes surprisingly showed a weak negative correlation in students' academic engagement and their achievement $(\mathrm{r}=-.088, \mathrm{p}>0.01)$. These results are in contrast with previous research findings. Previous studies therefore did not hold a consensus on the role of engagement on nursing students' academic performance.

On the other hand, it is worth noting that active learning indicates that the students are self-motivated to learn. Engagement should therefore have considered as a vital element dependent upon student's motivation to learn. Even if they are pretty poor in their knowledge or clinical skills, active learners should be concerned with finding the proper guidance of their academic and clinical educators. ${ }^{27}$ Maenpaa, Pyhalto, Jarvenoja and Peltonen (2018) ${ }^{28}$ recommended that nursing students who experience elevated levels of engagement are less likely to encounter an absence of vitality and to show a negative demeanor 
toward their studies. Engaged learners generatively interact with classmates and teachers in collaborative teaching learning activities with the aim of acquiring new knowledge. $^{29}$ In a study investigated the link between engagement and motivation, Oga-Baldwin and Nakata $(2017)^{30}$ indicated that engagement significantly predicted more intrinsically controlled adaptive motives and adversely predicted more extrinsic motives. In addition, Leong and Clutter $(2015)^{27}$ contended that knowing that active engagement will help them receive a better overall grade, students would be encouraged to look for learning opportunities and to demonstrate their sound knowledge and clinical nursing competencies. Student engagement is therefore commonly associated with clear and identifiable purposes or motives.

Numeral studies have been conducted to evaluate the role of student's motivation toward academic performance. Nursing education do not always provide an optimal learning environment for students. Regardless of the learning environment, however, it can be argued that nursing students benefit from well-developed motivation-regulation skills that can support students' learning and engagement. ${ }^{28}$ Motivation is frequently cited in the literature as being significant predictor of academic performance among nursing students contributing to study success.

Sturges, Maurer, Allen, Gatch and Shankar $(2015)^{31}$ results obtained from 1,210 students enrolled in undergraduate human anatomy and physiology (HAP) classes over a 2-year period indicated that there was a significant relationship between students' GPA, how many hours studying they reported, their overall self-reported motivation, and their academic performance. Maenpaa et al $(2018)^{28}$ contended that self-regulated motivation, engagement and students' well-being are critical components facilitating nursing students skillful self-regulated learning. Sharififard, Asayesh, Hosseini and Sepahvandi $(2020)^{32}$ conducted a descriptive-analytic study on 264 nursing and paramedical undergraduate students, based on the results of this study, internal motivation (IM), no motivation, and family/work and university management were identified as the most important moderating factors in academic burnout. They further added that IM increases the feelings of pleasure at the time of doing the work, and it is the basis of success among individuals. Sturges et al $(2015)^{31}$ defined IM toward accomplishments occurs when an individual engages in a behavior for the pleasure experienced while trying to accomplish a task or create something while external motivation (EM) represents actions taken to achieve a goal or reward beyond the activity itself.

Students who are intrinsically motivated see learning as opportunities to fulfill their own inquisitiveness and eagerness to learn. In contrast, students with an extrinsic motive aim to please others. ${ }^{33}$ Moreover, identifying what kind of motivation students use to assist them in their nursing education may be helpful to educators in guiding the student navigate their nursing education. Students need constructive and positive reinforcement from the teacher in the classroom to become verbally engaged in the classroom. ${ }^{34}$ In fact, both students' motivation to succeed and the support of the faculty to overcome difficulties during their studies, create resilience. Though, some research studies have demonstrated positive associations between intrinsic motivation and student's grades and a negative relationship between extrinsic motivation and academic outcomes. ${ }^{5,10,35}$ In turn, students should identify their goals of study and be motivated to commit and engage in this process. ${ }^{36}$ Leong and Clutter $(2015)^{27}$ emphasized that what motivates student performance toward successful academic performance is an area of concern and controversy to educators.

Additionally, it is worth noting that academic performance among nursing students is subject to influence of numerous factors. ${ }^{37}$ Besides engagement and motivation, several studies have explored sociodemographic factors influencing academic achievement. ${ }^{38,39}$ It is expected that students have a degree of motivation to reach this goal, their varied backgrounds often mean nursing faculty should use every opportunity required to understand what motivate them to engage with the learning process for the purpose of maximizing their academic performance. ${ }^{36}$

Taken together, it worth noting that student engagement has attracted substantial empirical interest of researchers, ascribable to the claims that engagement is associated with enhanced student's academic performance. However, the association between engagement, motivation and academic achievement is still unclear. Moreover, a scarce amount of research work has been conducted within this scope in the Arab region in general. It is therefore important to note first that the clearer our understanding of student achievement and the influences on it, the better positioned we will be to meet the needs of students, to enhance the student experience, and to improve the educational outcomes. It would be valuable to conduct further research to understand the complex interplay 
between engagement and motivation on academic achievement, also what factors affect engagement, motivation and achievement specially with the deficient local and international research in this area.

Second, although previous studies have relied principally on a single measure of engagement, the current study was based on a multi trait-multimethod design in which multiple engagement traits were measured through the use of battery of measures focusing on indicators and facilitators of student's college engagement. This method allowed for capturing the multidimensionality of the construct which add comprehensiveness and credibility to the evaluation of various aspects of the measurement model.

Finally, the current investigation acknowledges students' achievement, engagement and motivation can be influenced by a variety of demographic contextual factors which were therefore taken into consideration during study design. It is hoped that the findings of the current study could be used to assess opportunities for curricular development and design adjustments which could impact students' learning.

\section{Materials and Methods Aim of the Study}

The current study aimed to explore the relationship of learning engagement and motivation and their impact on academic performance of nursing students.

\section{Research Questions}

The three specific research questions of the study were to examine whether:

Research Question1: student perceptions of school engagement, motivation and performance are related differentially to the university campuses; Research Question 2: students' school engagement and motivation are associated with and have an influence on academic performance; and Research Question 3: the strength of associations among school engagement, motivation and achievement differ by students' background characteristics.

\section{Research Hypotheses}

For the first research question, it is hypothesized that each aspect of school engagement, motivation and the students' academic performance differs significantly among the three university's campuses (Hypothesis 1). For the second research question, the researchers hypothesized that students' level of school engagement and academic motivation predict their level of academic performance (Hypothesis 2). Finally, in the absence of a strong empirical basis for making predictions about whether the associations between perceived school engagement, motivation, academic performance will function differently for campus, authors treated the age, academic level, family income, number of children, siblings and academic progress analyses as exploratory (Hypothesis 3).

The research conceptual model is shown in Figure 1. The basis for this conceptual framework, are the findings in earlier research suggesting that student engagement, motivation, and students' background are precursors for academic achievement. ${ }^{40,41}$

\section{Study Design and Setting}

A descriptive survey design, with a comparative correlational approach for data analysis was utilized to describe and compare engagement among undergraduate nursing students at King Saud bin Abdul-Aziz University for Health Sciences. The multisite, multilevel nature of students was considered through careful sampling to ensure satisfactory recruitment from each academic level and academic year in each campus, increase access to subjects and richness of the data and to improve research results generalizability. Data was therefore collected from nursing colleges in the three campuses of King Saud bin AbdulAziz University for Health Sciences (Riyadh, Jeddah and Alhasa). The associations among the study variables were explored. Moreover, factors related to academic engagement, motivation, and performance of students enrolled in the baccalaureate-nursing program, were examined.

\section{Population and Sample Size}

Students enrolled in Baccalaureate program in the nursing colleges at Riyadh, Jeddah and Alhasa constituted the study subjects. This is a four-year program with a total of 136 credit hours that offers a baccalaureate of science in nursing designated for secondary school graduates. The baccalaureate program starts with two pre-professional years (level 1 to level 4) for building students' foundation in humanities, social/behavioral, biological and health sciences, health informatics sciences as well as general basic nursing fundamental concepts. The last two professional years (level 5 to level 8) focus on building professional nursing knowledge and clinical practice.

Inclusion criteria for participants were: enrollment in professional years of the nursing program (level 5 to 


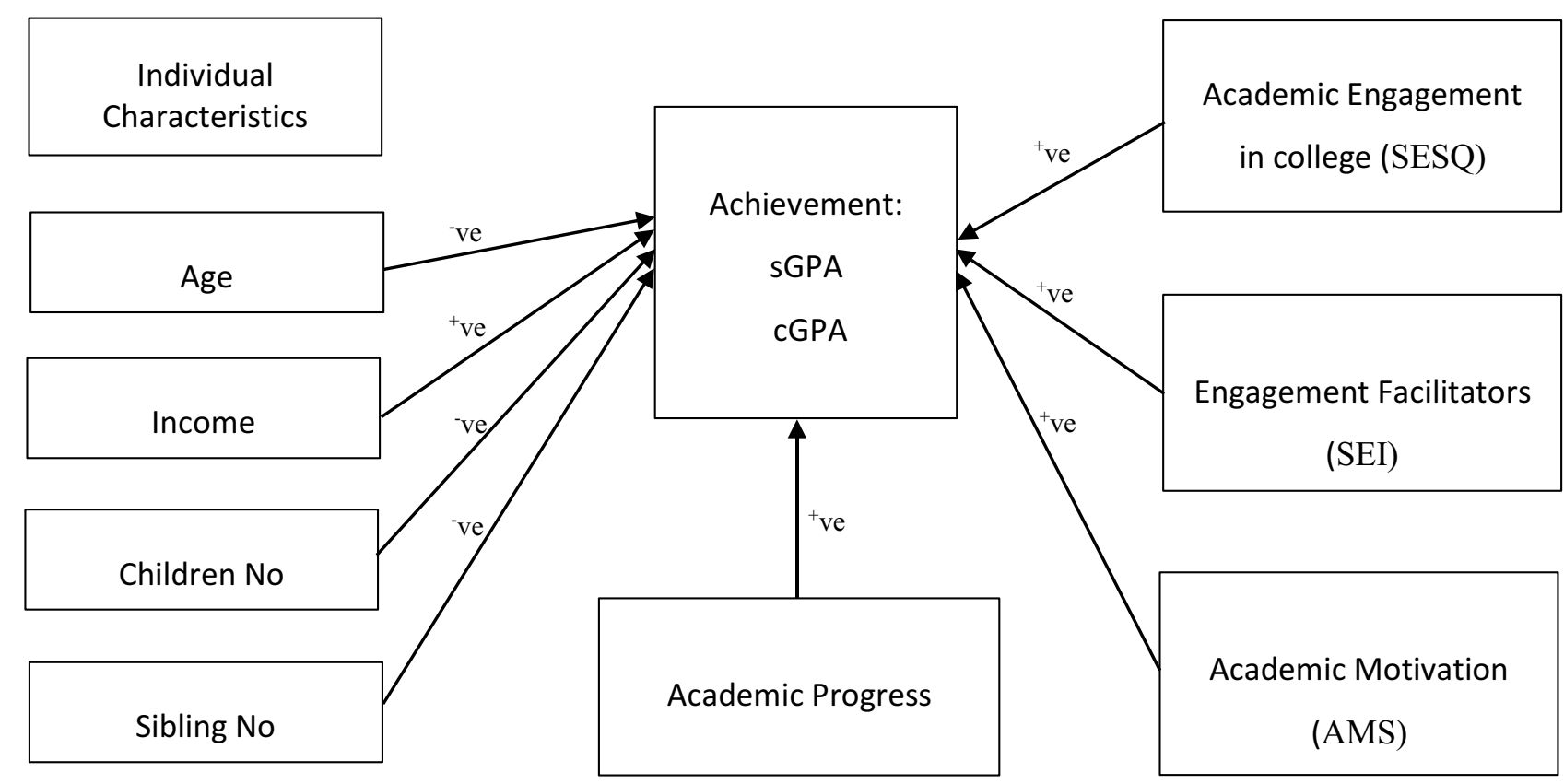

Figure I Proposed Research Model Predicting Student's Academic Achievement.

level 8); willingness to participate and signing the written informed consent. An estimated total number of accessible population of 634 students were enrolled at spring semester in the different professional nursing levels at the three campuses: (200, 201, 233; respectively in Riyadh, Jeddah, and Alhasa). A priori estimation of the sample size was made using an alpha set at 0.05 with a power of 0.9 to anticipate a medium effect size of 0.3 . A projected sample of at least $\approx 300$ participants was desired. Giving the possibilities for both having some missing data as well as some expected non-response rate, all accessible sample per campus were invited for participation in the study. A total of 425 who met the inclusion criteria were recruited for participation in the study using a convenient sampling technique. To ensure satisfactory recruitment from each academic level and academic year in each campus, researchers made sure that $\approx 30$ or more students were recruited from each level/campus. Convenience sampling technique is an easy and cheap method of sampling for recruiting subjects for the data collection in each stratum (level in the nursing program/campus).

\section{Data Collection and Procedure}

Study instruments that were utilized for data collection, included the sociodemographic and education-background sheet, college engagement, engagement facilitators, motivation and academic achievement questionnaires.
Demographic and education-related background characteristics sheet was developed by the investigators. It has several items collecting information related to student's age, marital status, income, number of children, number of siblings, year of study, and academic level (i.e., level is same as semester of study, so the four-year academic program consists of eight levels of study). Academic progress status was also measured where students were requested to indicate whether they dropped a semester or more (score 1), dropped a course or more (score 2), repeated a course or more (score 3), or are regular (score 4).

A variety of measures of students' engagement were utilized because of the multidimensionality of the construct. For purposes of this study, the researchers utilized two scales focusing on indicators and facilitators of student's college engagement. These were Student Engagement in Schools Questionnaire (SESQ-ENG) that capture affective, behavioral and cognitive indicators of engagement and Student Engagement Instrument (SEI) which measure facilitators among study subjects. The SESQ is developed by scholars from more than 19 countries. Items were drawn from existing research, increasing the content validity of the measure. ${ }^{42}$ SESQ contains four composites (i.e., student engagement in the schools, motivational beliefs, social-relatedness contexts, student outcomes). For the purposes of this study, only the composite 
of Student Engagement in Schools (SESQ-ENG; 33 items) was utilized to measure indicators of engagement (i.e., affective, behavioral, and cognitive). It is composed of five factors (affective engagement: liking for learning; affective engagement: liking for school; behavioral engagement: effort and persistence; behavioral engagement: extracurricular activities; and cognitive engagement). SESQ item response choices are based upon a 5-point Likert-type scale (i.e., "1" indicates "never," "2" indicates "rarely," "3" indicates "sometimes," "4" indicates "often," " 5 " indicates "always"). Estimates of internal consistency for the SESQ domains range from $0.65 \leq \alpha \leq 0.95$. Additionally, this scale has a good reported overall internal consistency $(\alpha>0.70)^{43}$ and the score for validity is 0.45 . $^{42}$

The SEI was developed by Appleton, Christenson, Kim and Reschly (2006). ${ }^{44}$ It is a well validated 35-item Likerttype self-report measure the cognitive and psychological components of student engagement. This instrument measures student's engagement by considering how different contexts (e.g., family, peers, schools) may influence students. This include (the quality of the teacher-student relationship, control and relevance of school work, peer support to learning, future goals and aspirations, family support for learning). The SEI survey item response choices are based upon a 4-point Likert-type scale (i.e., " 1 " indicates "strongly disagree," "2" indicates "disagree," "3" indicates "agree," “4" indicates "strongly agree") Coefficient alphas as evidence of internal consistency are: teacher-student relationships $(\alpha=0.88)$, control and relevance of school work $(\alpha=0.80)$, peer support for learning ( $\mathrm{r} \alpha=0.82)$, future aspirations and goals $(\alpha=$ $0.78)$, family support for learning $(\alpha=0.76)$. Scale scores correlated positively with academic variables including students' GPA. ${ }^{44}$

In addition, student's motivation for learning was measured using the Academic Motivation Scale (AMS) developed by Vallerand et al (1992). ${ }^{45}$ It measures motivation, external regulation, introjected regulation, identified regulation, and intrinsic motivation. Response for each item rated on a 5-point Likert scale ranging from 0 (does not correspond at all) to 7 (corresponds exactly). Alivernini and Lucidi $(2008)^{46}$ provided adequate support for the factorial validity and reliability of the AMS use in educational research on motivation. Moreover, test-retest correlations of AMS were found between 0.79 and 0.91 by Haslofçala and Korkmaz (2016). ${ }^{47}$
Finally, student's academic achievement being vital indicator of academic success and one of the main outcomes of current study, was measured using students' selfreport of their cumulative grade point average (cGPA) (i. e., a calculation used to determine overall academic performance) and last semester grade point average (sGPA).

\section{Ethical Considerations}

The research proposal was submitted for scientific approval and ethical review to King Abdullah International Medical Research Center (KAIMRC). A cover letter and a copy of the approval were sent to the nursing dean of each sister nursing colleges in Riyadh (CON-R), Jeddah (CON-J) and Alhasa (CON-A) with requests to get their administrative approval of data collection process. Nursing students from the three sister colleges were then approached to explain the purpose and procedure of the research study. They were assured that participation was on a voluntary basis and they could withdraw from the study at any time. They were also assured that neither rejection of participation nor withdrawal at any point would have any impact on their studies.

Students were informed that their responses to study questionnaire are kept private, confidential and anonymous throughout the data collection, management, and the publication process. They were further informed that no identifier is required in their questionnaire, and no one would access their data except the research investigators and that dissemination of study findings are done using aggregate score to ensure their rights for privacy, confidentiality and anonymity. Once students voluntarily signed the informed consent, they were requested to fill the study questionnaires. Instructions regarding the questionnaires were provided in writing along the study questionnaire to volunteering students.

\section{Statistical Analysis}

Statistical analyses were conducted using SPSS Version 20. Data was first screened for missing data, normality, and outliers. Descriptive information reported by way of mean and standard deviation for quantitative normally distributed variables while frequencies and percentages were used for describing qualitative type of data. Parametric inferential statistics included (ANOVA, Pearson correlation and regression analysis). Significance level was set at $\mathrm{p}<0.05$. 


\section{Results}

The average age for study subjects was 21.52 years $(\mathrm{SD}=1.12)$. Concerning marital status, $86.4 \%$ were singles and this constituted $29.9 \%$ from Jeddah, 29.6\% from Alhasa compared to $26.8 \%$ from Riyadh. Most of married students were from Alhasa campus (8.7\%). Students' sGPA was slightly higher than average cumulative cGPA (3.61 $\pm 0.65,3.59 \pm 0.59$, respectively). However, students' semester and cumulative GPA did not vary by campus $(\mathrm{F}=0.23, \mathrm{p}=0.79, \mathrm{~F}=2.92, \mathrm{p}=0.06$; respectively). Overall, level five students constituted majority of the sample $(40.0 \%)$, but the academic level distribution varied by campus $\left(x^{2}=34.84, \mathrm{p}<0.001\right)$. Students were recruited from year three $(60.2 \%)$ and year four $(39.8 \%)$, no recruitment made from year one and two as students there are still in their pre-professional years that prepare them for the rest of their coming advanced nursing program. Although the majority of the sample were regular students $(76.0 \%)$, most of them (31.3\%) were from the Alhasa campus $\left(x^{2}=36.37, \mathrm{p}<0.001\right.$; Table 1$)$.

\section{Are There Any Differences in Engagement Perceptions, Engagement Facilitators and Academic Motivation Among Nursing Students in the Three University Campuses?}

Overall, respondents reported moderate levels of engagement in school as shown by their SESQ total mean score of $3.70(\mathrm{SD}=0.63)$ out of a total of 5 points. There were statistically significant differences between the three campuses as determined by one-way ANOVA $(\mathrm{F}=18.88, \mathrm{p} \leq$

Table I Demographic and Educational Background for Study Participants ( $N=425)$

\begin{tabular}{|c|c|c|c|c|c|c|c|}
\hline \multicolumn{2}{|l|}{ Variable } & \multicolumn{3}{|l|}{ Campus } & \multirow{4}{*}{$\begin{array}{l}\text { Total } \\
\text { Mean(SD) } \\
21.52(1.12)\end{array}$} & \multirow{4}{*}{$\begin{array}{l}\mathbf{F} \\
\\
6.54\end{array}$} & \multirow{4}{*}{$\begin{array}{l}P \\
0.002\end{array}$} \\
\hline & & \multirow{3}{*}{$\begin{array}{l}\text { Riyadh } \\
\text { Mean(SD) } \\
21.77(1.07)\end{array}$} & \multirow{3}{*}{$\begin{array}{l}\text { Jeddah } \\
\text { Mean(SD) } \\
21.74(1.12)\end{array}$} & \multirow{3}{*}{$\begin{array}{l}\text { Alhasa } \\
\text { Mean(SD) } \\
21.08(1.05)\end{array}$} & & & \\
\hline & & & & & & & \\
\hline Age & $\begin{array}{l}\operatorname{Min}=20.0 \\
\operatorname{Max}=27.0\end{array}$ & & & & & & \\
\hline sGPA & $\begin{array}{l}\operatorname{Min}=2.0 \\
\operatorname{Max}=5.0\end{array}$ & $3.62(0.85)$ & $3.64(0.55)$ & $3.57(0.59)$ & $3.6 \mathrm{I}(0.65)$ & 0.23 & 0.79 \\
\hline cGPA & $\begin{array}{l}\operatorname{Min}=2.0 \\
\operatorname{Max}=4.9\end{array}$ & $3.46(0.7 I)$ & $3.59(0.56)$ & $3.69(0.55)$ & $3.59(0.59)$ & 2.92 & 0.06 \\
\hline \multicolumn{2}{|l|}{ Variable } & Riyadh & Jeddah & Alhasa & Total N(\%) & $\chi^{2}$ & $p$ \\
\hline Marital & $\begin{array}{l}\text { Single } \\
\text { Married } \\
\text { Divorced } \\
\text { Widow } \\
\mathrm{N}(\%)\end{array}$ & $\begin{array}{l}I I 4(26.8) \\
8(1.9) \\
I(0.2) \\
0(0.0) \\
I 23(28.9)\end{array}$ & $\begin{array}{l}127(29.9) \\
I \mid(2.6) \\
0(0.0) \\
0(0.0) \\
138(32.5)\end{array}$ & $\begin{array}{l}126(29.6) \\
37(8.7) \\
0(0.0) \\
I(0.2) \\
164(38.6)\end{array}$ & $\begin{array}{l}367(86.4) \\
56(13.2) \\
I(0.2) \\
I(0.2) \\
425(100.0)\end{array}$ & 24.81 & 0.000 \\
\hline Academic year & $\begin{array}{l}\text { Three } \\
\text { Four } \\
\mathrm{N}(\%)\end{array}$ & $\begin{array}{l}72(16.9) \\
51(12.0) \\
123(28.9)\end{array}$ & $\begin{array}{l}66(15.5) \\
72(16.9) \\
138(32.5)\end{array}$ & $\begin{array}{l}118(27.8) \\
46(10.8) \\
164(38.6)\end{array}$ & $\begin{array}{l}256(60.2) \\
169(39.8) \\
425(100.0)\end{array}$ & 18.42 & 0.000 \\
\hline Education level & $\begin{array}{l}\text { Five } \\
\text { Six } \\
\text { Seven } \\
\text { Eight } \\
\mathrm{N}(\%)\end{array}$ & $\begin{array}{l}46(10.8) \\
26(6.1) \\
21(4.9) \\
30(7.1) \\
123(28.9)\end{array}$ & $\begin{array}{l}33(7.8) \\
33(7.8) \\
38(8.9) \\
34(8.0) \\
138(32.5)\end{array}$ & $\begin{array}{l}91(21.4) \\
29(6.8) \\
23(5.4) \\
21(4.9) \\
164(38.6)\end{array}$ & $\begin{array}{l}170(40.0) \\
88(20.7) \\
82(19.3) \\
85(20.0) \\
425(100.0)\end{array}$ & 34.84 & 0.000 \\
\hline Academic progress & $\begin{array}{l}\text { Regular study } \\
\text { Dropped semester } \\
\text { Dropped course/s } \\
\text { Repeated course/s } \\
\mathrm{N}(\%)\end{array}$ & $\begin{array}{l}71(16.7) \\
11(2.6) \\
11(2.6) \\
30(7.1) \\
123(28.9)\end{array}$ & $\begin{array}{l}119(28.0) \\
3(0.7) \\
6(1.4) \\
10(2.4) \\
138(32.5)\end{array}$ & $\begin{array}{l}133(31.3) \\
5(1.2) \\
3(0.7) \\
23(5.4) \\
164(38.6)\end{array}$ & $\begin{array}{l}323(76.0) \\
19(4.5) \\
20(4.7) \\
63(14.8) \\
425(100.0)\end{array}$ & 36.37 & 0.000 \\
\hline
\end{tabular}


001). A Tukey post hoc test revealed that the levels of engagement in school was statistically significantly higher in Alhasa campus (Mean $=3.87 \pm 0.48, \mathrm{p} \leq .001)$ and Riyadh campus (Mean $=3.76 \pm 0.68, \mathrm{p} \leq .001$ ) compared to Jeddah campus (Mean $=3.44 \pm 0.67$ ) with no statistically significant difference between the Riyadh and Alhasa campuses on levels of engagement in school $(p=0.286)$. Total mean scores on all six SESQ indicators were relatively high (Mean range $=3.22-3.97$, SD range $=0.54-1.14$ ) and all varied by campus. Results show that interest in learning was ranked the first (Mean $=3.97 \pm 1.08$ ), followed by cognitive engagement $($ Mean $=3.90 \pm 0.91)$ and affective liking for school (Mean $=3.78 \pm 1.03$ ), respectively.

The assessment of students' engagement as measured by SEI reveals that students had a high level for facilitators of engagement with a mean score of $2.98(\mathrm{SD}=0.49)$ out of a total of 4 points, but it did vary by campus $(\mathrm{F}=6.35$, $\mathrm{p}=0.002$ ). A Tukey post hoc test further revealed that the level of engagement facilitators was statistically significantly higher in Riyadh campus (Mean $=3.02 \pm 0.60$, $\mathrm{p}=0.024$ ) and Alhasa campus (Mean $=3.05 \pm 0.39$, $\mathrm{p}=0.002$ ) compared to Jeddah campus (Mean=2.86 \pm 0.45 ). Again, there was no statistically significant difference between the Riyadh and Alhasa campuses on levels of total engagement in school, both similarly rated high ( $p$ $=0.824)$. With regard to SEI five facilitators of engagement, the findings indicate the factor with the highest mean score was the future goals and aspirations (Mean=3.48 \pm 0.47 ), followed by family support for learning (Mean=3.33 \pm 0.52 ), and control and relevance of schoolwork (Mean=3.18 \pm 0.41 ), respectively. A Tukey post hoc test revealed that all but the two domains of control and relevance of schoolwork and peer support for learning, showed no difference between Riyadh and Jeddah but Alhasa was significantly higher. So research hypothesis 1 is supported. Table 2 .

As shown in Table 3, study participants reported high levels of academic motivation (Mean=4.89 out of a total of 7 points, $\mathrm{SD}=1.03)$, and it did vary by campus $(\mathrm{F}=9.85$, $\mathrm{p} \leq .001$ ). A Tukey post hoc test revealed that the levels of academic motivations among students was statistically significantly higher in Alhasa campus (Mean=5.11 \pm 1.00 , $\mathrm{p} \leq .001$ ), followed by Riyadh campus (Mean $=4.94 \pm 1.00$,

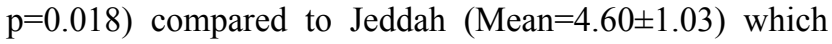
showed the lowest total mean score. These findings lend additional support for research hypothesis 1 .

The mean scores on all five-perceived academic motivation indicators were moderate to high (Mean range $=4.49-5.16, \mathrm{SD}$; range $=1.03-1.77)$. The differences between students of the three campuses, in the different components of academic motivation were all statistically significant. Moreover, intrinsic regulation was ranked first (Mean $=5.16)$, followed by identified regulation (Mean = 5.09) and introjected regulation (Mean $=5.04$ ), respectively.

\section{Are There Any Associations Between Students' School Engagement, Motivation, Academic Achievement and Their Background Characteristics?}

Correlational analyses were used to examine the relationships between students' learning engagement, motivation, academic performance scores and background variables. The correlations matrix using Pearson $r$, showed that there was wide range of values from trivial-to-large $(\mathrm{r}=0.00$ 0.92). The correlations between the study factors of engagement, motivation, and academic performance scores indicated medium to large correlations (i.e., between $0.20-0.63)$. The majority of the correlations were significant at $\mathrm{p}<0.01$.

Results further indicated that academic performance as measured by SGPA and cGPA was positively correlated with SESQ total score $(r=0.34, r=0.30$, at $\mathrm{p}<0.01)$, AMS total score $(r=0.26, r=0.21$ at $p<0.01)$ and SEI total score $(r=0.20, r=0.22, p<0.01)$. This infers that students, who have higher level of school engagement and engagement facilitation are more likely to have higher academic performance. There was a high correlation between academic motivation and engagement. Total AMS score was positively correlated with SESQ total score $(\mathrm{r}=0.54, \mathrm{p}<0.01)$ and SEI total score $(\mathrm{r}=0.44$, $\mathrm{p}<0.01)$. Further, SESQ total score was also positively correlated with SEI total score $(\mathrm{r}=0.63, \mathrm{p}<0.01)$.

Academic level correlated with many of the research variables and composite scores, including SESQ behavioral efforts and persistence $(r=-.12, p<0.05)$, SESQ cognitive $(\mathrm{r}=-.14, \mathrm{p}<0.01)$, SESQ total score $(\mathrm{r}=-.13$, $\mathrm{p}<0.01)$, AMS introjected regulation $(\mathrm{r}=-.12, \mathrm{p}<0.05)$, AMS identified regulation $(\mathrm{r}=-.12, \mathrm{p}<0.05)$, AMS intrinsic regulation $(\mathrm{r}=-.12, \mathrm{p}<0.05)$, AMS total score $(\mathrm{r}=-.13, \mathrm{p}<0.01)$, SEI teacher-student relationship $(\mathrm{r}=$ $0.10, \mathrm{p}<0.05)$, SEI future goals and aspirations $(\mathrm{r}=-.18$, $\mathrm{p}<0.01)$ and SEI family support for learning and SEI total score $(\mathrm{r}=-.13, \mathrm{p}<0.01)$. Academic progress had few significant correlations with SESQ behavioral efforts and 
Table 2 Engagement Indicators and Facilitators Among Study Participants ( $N=425)$

\begin{tabular}{|c|c|c|c|c|c|c|c|}
\hline \multirow[t]{3}{*}{ Variables } & & \multicolumn{3}{|l|}{ Campus } & \multirow{3}{*}{$\begin{array}{l}\text { Total } \\
\text { Mean(SD) }\end{array}$} & \multirow[t]{3}{*}{$\mathbf{F}$} & \multirow[t]{3}{*}{$p$} \\
\hline & & \multirow{2}{*}{$\begin{array}{l}\text { Riyadh } \\
\mathrm{N}=123\end{array}$} & \multirow{2}{*}{$\begin{array}{l}\text { Jeddah } \\
\mathrm{N}=138\end{array}$} & \multirow{2}{*}{$\begin{array}{l}\text { Alhasa } \\
\mathrm{N}=164\end{array}$} & & & \\
\hline & & & & & & & \\
\hline \multicolumn{8}{|c|}{ Student Engagement in Schools Questionnaire (SESQ) } \\
\hline Interest in learning & $\begin{array}{l}\operatorname{Min}=1.00 \\
\operatorname{Max}=5.00 \\
S E=0.05\end{array}$ & $4.15(1.07)$ & $3.81(1.09)$ & $3.98(1.05)$ & $3.97(1.08)$ & 3.189 & 0.042 \\
\hline Affective liking for learning & $\begin{array}{l}\operatorname{Min}=1.25 \\
\operatorname{Max}=5.00 \\
S E=0.04\end{array}$ & $3.74(0.76)$ & $3.44(0.75)$ & $3.73(0.77)$ & $3.64(0.77)$ & 6.68 & 0.001 \\
\hline Affective liking for school & $\begin{array}{l}\operatorname{Min}=1.00 \\
\operatorname{Max}=5.00 \\
S E=0.05\end{array}$ & $3.79(1.01)$ & $3.59(1.11)$ & $3.94(0.94)$ & $3.78(1.03)$ & 4.49 & 0.012 \\
\hline Behavioral efforts and persistence & $\begin{array}{l}\operatorname{Min}=2.00 \\
\operatorname{Max}=5.00 \\
S E=0.03\end{array}$ & $3.62(0.56)$ & $3.35(0.54)$ & $3.65(0.47)$ & $3.55(0.54)$ & 14.69 & 0.000 \\
\hline Behavioral extracurricular & $\begin{array}{l}\operatorname{Min}=1.00 \\
\operatorname{Max}=5.00 \\
S E=0.06\end{array}$ & $3.34(1.19)$ & $2.84(1.08)$ & $3.44(1.07)$ & $3.22(1.14)$ & 14.69 & 0.000 \\
\hline Cognitive & $\begin{array}{l}\operatorname{Min}=1.00 \\
M a x=5.00 \\
S E=0.04\end{array}$ & $3.92(0.98)$ & $3.59(1.00)$ & $4.15(0.67)$ & $3.90(0.91)$ & 14.99 & 0.000 \\
\hline SESQ Total & $\begin{array}{l}\operatorname{Min}=1.48 \\
\operatorname{Max}=4.76 \\
S E=0.03\end{array}$ & $3.76(0.68)$ & $3.44(0.67)$ & $3.87(0.48)$ & $3.70(0.63)$ & 18.88 & 0.000 \\
\hline \multicolumn{8}{|c|}{ Student Engagement Instrument (SEI) } \\
\hline Teacher-Student Relationship & $\begin{array}{l}\operatorname{Min}=1.00 \\
\operatorname{Max}=4.00 \\
S E=0.03\end{array}$ & $2.94(0.62)$ & $2.78(0.52)$ & $2.76(0.60)$ & $2.82(0.58)$ & 3.92 & 0.021 \\
\hline Control and Relevance of Schoolwork & $\begin{array}{l}\operatorname{Min}=1.00 \\
\operatorname{Max}=4.00 \\
S E=0.03\end{array}$ & $3.10(0.62)$ & $2.92(0.50)$ & $3.18(0.41)$ & $3.07(0.52)$ & 9.92 & 0.000 \\
\hline Peer Support for Learning & $\begin{array}{l}\operatorname{Min}=1.00 \\
\operatorname{Max}=4.00 \\
S E=0.03\end{array}$ & $3.05(0.67)$ & $2.85(0.57)$ & $3.12(0.53)$ & $3.01(0.60)$ & 8.46 & 0.000 \\
\hline Future Goals and Aspirations & $\begin{array}{l}\operatorname{Min}=1.00 \\
\operatorname{Max}=4.00 \\
S E=0.03\end{array}$ & $3.19(0.69)$ & $3.09(0.59)$ & $3.48(0.47)$ & $3.27(0.60)$ & 18.37 & 0.000 \\
\hline Family Support for Learning & $\begin{array}{l}\operatorname{Min}=1.00 \\
\operatorname{Max}=4.00 \\
S E=0.03\end{array}$ & $3.07(0.7 I)$ & $2.92(0.59)$ & $3.33(0.52)$ & $3.12(0.62)$ & $17.88 \mid$ & 0.000 \\
\hline SEl Total & $\begin{array}{l}\operatorname{Min}=1.00 \\
\operatorname{Max}=4.00 \\
S E=0.02\end{array}$ & $3.02(0.60)$ & $2.86(0.45)$ & $3.05(0.39)$ & $2.98(0.49)$ & 6.35 & 0.002 \\
\hline
\end{tabular}


Table 3 Academic Motivation Among Study Respondents (N=425)

\begin{tabular}{|c|c|c|c|c|c|c|c|}
\hline \multicolumn{2}{|l|}{ Variables } & \multicolumn{3}{|l|}{ Campus } & \multirow{3}{*}{$\begin{array}{l}\text { Total } \\
\text { Mean(SD) }\end{array}$} & \multirow[t]{3}{*}{$\mathbf{F}$} & \multirow[t]{3}{*}{$p$} \\
\hline & & \multirow{2}{*}{$\begin{array}{l}\text { Riyadh } \\
\mathrm{N}=123 \\
\text { Mean(SD) }\end{array}$} & \multirow{2}{*}{$\begin{array}{l}\text { Jeddah } \\
\mathrm{N}=138 \\
\text { Mean(SD) }\end{array}$} & \multirow{2}{*}{$\begin{array}{l}\text { Alhasa } \\
\mathrm{N}=164 \\
\text { Mean(SD) }\end{array}$} & & & \\
\hline & & & & & & & \\
\hline Amotivation & $\begin{array}{l}\operatorname{Min}=1.00 \\
M a x=7.00 \\
S E=0.09\end{array}$ & $4.22(1.95)$ & $4.78(1.50)$ & $4.47(I .82)$ & $4.49(1.77)$ & 3.23 & $0.04 I$ \\
\hline External Regulation & $\begin{array}{l}\operatorname{Min}=1.00 \\
\operatorname{Max}=7.00 \\
S E=0.07\end{array}$ & $4.77(1.61)$ & $4.25(1.35)$ & $5.04(I .4 I)$ & $4.70(1.48)$ & 11.12 & 0.000 \\
\hline Introjected Regulation & $\begin{array}{l}\operatorname{Min}=1.00 \\
\operatorname{Max}=7.00 \\
S E=0.08\end{array}$ & $5.12(1.54)$ & $4.49(1.55)$ & $5.44(\mathrm{I} .43)$ & $5.04(1.55)$ & 14.90 & 0.000 \\
\hline Identified Regulation & $\begin{array}{l}\operatorname{Min}=1.00 \\
\operatorname{Max}=7.00 \\
S E=0.07\end{array}$ & $5.27(1.50)$ & $4.69(1.42)$ & $5.29(1.46)$ & $5.09(1.48)$ & 7.68 & 0.001 \\
\hline Intrinsic Regulation & $\begin{array}{l}\operatorname{Min}=1.00 \\
\operatorname{Max}=7.00 \\
S E=0.08\end{array}$ & $5.35(1.55)$ & $4.80(1.65)$ & $5.32(1.37)$ & $5.16(1.53)$ & 5.69 & 0.004 \\
\hline AMS Total & $\begin{array}{l}\operatorname{Min}=2.10 \\
M a x=7.00 \\
S E=0.05\end{array}$ & $4.94(1.00)$ & $4.60(1.03)$ & $5.11(1.00)$ & $4.89(1.03)$ & 9.85 & 0.000 \\
\hline
\end{tabular}

persistence $(\mathrm{r}=-.14, \mathrm{p}<0.01)$, SESQ behavioral extracurricular $(\mathrm{r}=0.10, \mathrm{p}<0.05)$, AMS amotivation $(\mathrm{r}=-.13$, $\mathrm{p}<0.05)$ and SEI teacher-student relationship $(\mathrm{r}=0.11$, $\mathrm{p}<0.05)$. No significant correlations were found between age, family income, number of children, and number of siblings with other research variables. The results from the correlation analyses of the research variables are presented in Table 4.

\section{What is the Effect of School Engagement, Motivation and Background Characteristics on Nursing Students' Academic Performance?}

Multiple regression analysis was used to identify whether students' significant background characteristics, engagement and motivation predict academic performance variance. It is worth noting that in all the regressions, all predictors are examined as overall scales. Two separate multiple regression were performed to predict student's academic performance (cGPA, sGPA), using five independent variables (i.e., students' background characteristics, learning engagement and motivation) as the predictors. The summary of regression analyses is presented in Table 5. For each regression, the beta-coefficient (b), standardized beta-coefficient $(\beta)$, the adjusted coefficient of determination (R2) and the significance (p) are displayed in Table 5.

The overall regression equation including all five sets of variables of age, academic progress, academic engagement, motivation and engagement facilitators on cGPA score was statistically significant $(\mathrm{F}(5,226)=14.209$, $\mathrm{p}<0.001, \mathrm{R}^{2}=0.239$, Adjusted $\mathrm{R}^{2}=0.222$ ). Taken together these five sets of variables explained almost $24 \%$ of the variance in cGPA scores. Comparison of the relative magnitudes of the standardized regression coefficients for cGPA indicated that academic progress $(\beta=$ 0.32) was the most important predictor of students' cGPA, hypothesis 3 is supported. SESQ Total $(\beta=0.18$, supporting hypothesis 2) was the second most important predictor, followed by age $(\beta=-.12$, supporting hypothesis 3$)$. While it is worth noting that while the $p$ values are not very strong, coefficients for SEI Total $(\beta=0.09$, $\mathrm{p}=0.240$, not supporting hypothesis 2$)$, and AMS Total $(\beta$ 


\begin{tabular}{|c|}
\hline$\underline{8}$ \\
\hline$\stackrel{8}{\mathrm{a}}$ \\
\hline 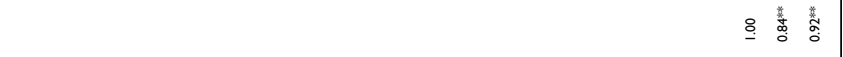 \\
\hline 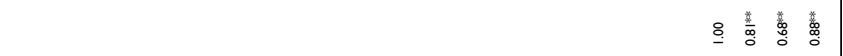 \\
\hline 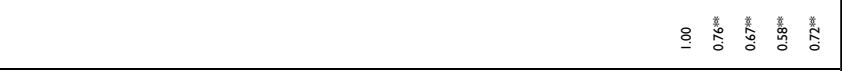 \\
\hline 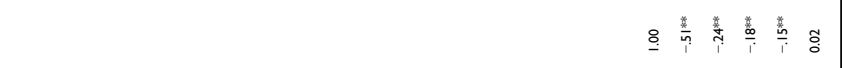 \\
\hline 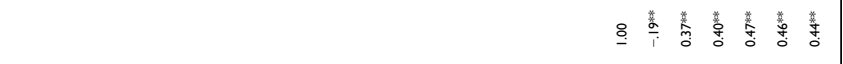 \\
\hline 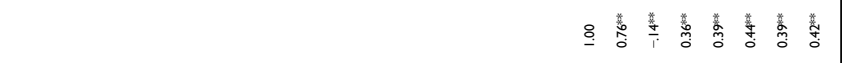 \\
\hline 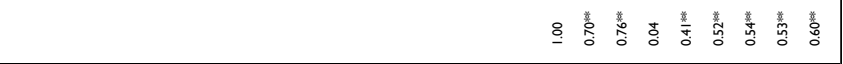 \\
\hline 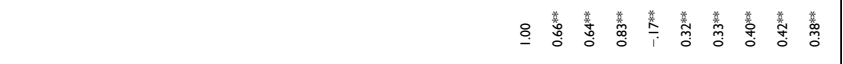 \\
\hline 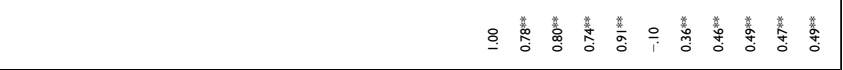 \\
\hline 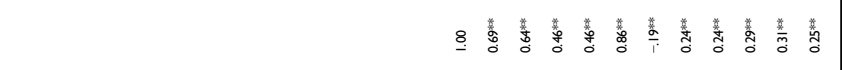 \\
\hline 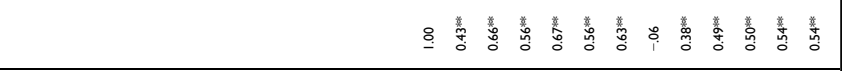 \\
\hline 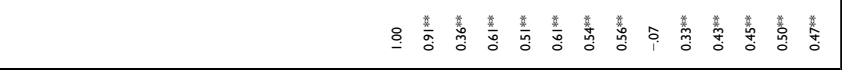 \\
\hline 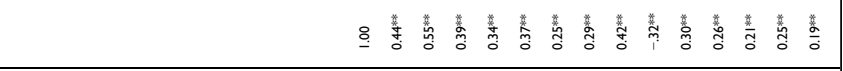 \\
\hline 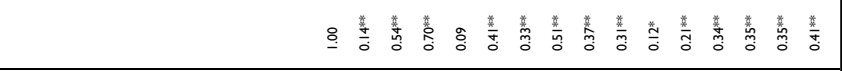 \\
\hline 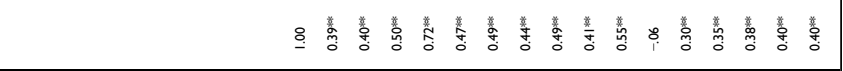 \\
\hline 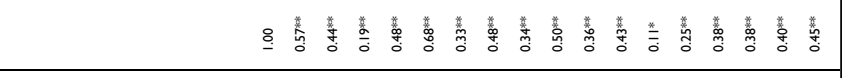 \\
\hline 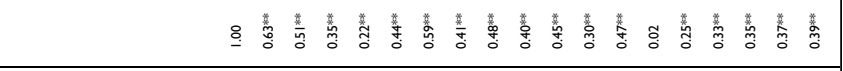 \\
\hline 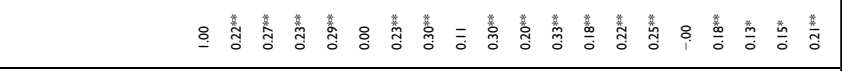 \\
\hline 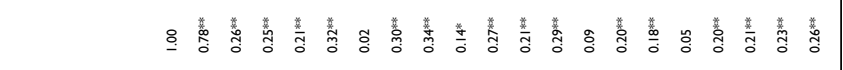 \\
\hline 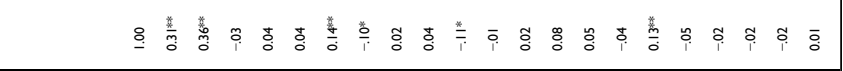 \\
\hline 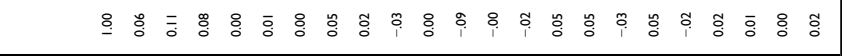 \\
\hline 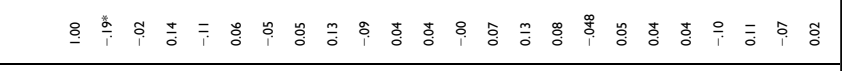 \\
\hline 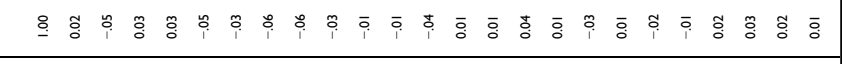 \\
\hline 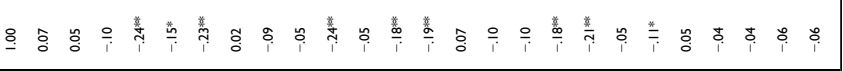 \\
\hline 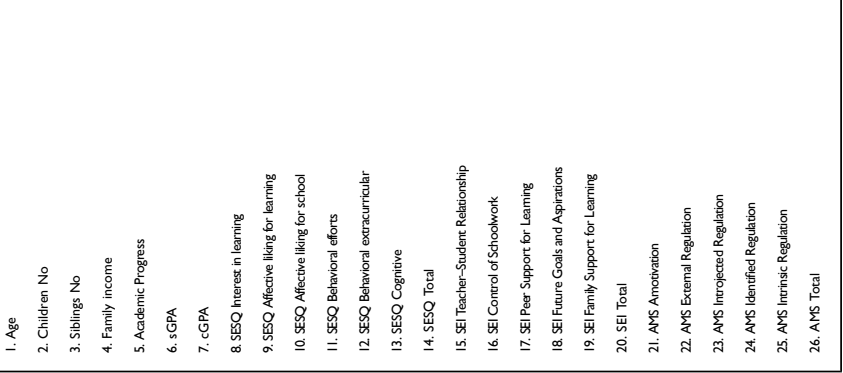 \\
\hline
\end{tabular}


Table 5 Multiple Linear Regression Model to Predict Academic Performance Among Nursing Students (N=425)

\begin{tabular}{|c|c|c|c|c|c|c|c|c|c|c|c|c|}
\hline & \multicolumn{6}{|c|}{ cGPA } & \multicolumn{6}{|c|}{ sGPA } \\
\hline & b & SE B & $\boldsymbol{\beta}$ & $\mathbf{t}$ & $\mathbf{p}$ & VIF & b & SE B & $\beta$ & $\mathbf{t}$ & $\mathbf{p}$ & VIF \\
\hline Constant & 3.83 & 0.75 & - & 5.14 & 0.000 & & 2.46 & 0.88 & - & 2.79 & 0.006 & \\
\hline Age & -.06 & 0.03 & -.12 & -1.93 & 0.047 & 1.08 & $-.0 \mathrm{I}$ & 0.04 & -.01 & -.19 & 0.85 & 1.12 \\
\hline Academic Progress & 0.11 & 0.02 & 0.32 & 5.32 & 0.000 & 1.08 & 0.10 & 0.02 & 0.28 & 4.45 & 0.000 & 1.11 \\
\hline SESQ Total & 0.17 & 0.08 & 0.18 & 2.24 & 0.026 & 1.83 & 0.24 & 0.10 & 0.22 & 2.48 & 0.014 & 2.18 \\
\hline SEI Total & 0.12 & 0.10 & 0.09 & 1.18 & 0.240 & 1.58 & 0.03 & 0.11 & 0.02 & 0.30 & 0.76 & 1.65 \\
\hline AMS Total & 0.06 & 0.04 & 0.11 & 1.55 & 0.122 & 1.38 & 0.11 & 0.047 & 0.17 & 2.28 & 0.024 & 1.61 \\
\hline $\mathrm{R}^{2}$ & \multicolumn{6}{|c|}{0.239} & \multicolumn{6}{|l|}{0.222} \\
\hline Adjusted $R^{2}$ & \multicolumn{6}{|c|}{0.222} & \multicolumn{6}{|c|}{0.204} \\
\hline $\mathrm{F}$ & \multicolumn{6}{|c|}{14.209} & \multicolumn{6}{|c|}{12.202} \\
\hline $\mathrm{p}$-value & \multicolumn{6}{|c|}{0.000} & \multicolumn{6}{|l|}{0.000} \\
\hline
\end{tabular}

$=0.11, \mathrm{p}=0.122$, not supporting hypothesis 2 ) have noticeable positive contribution to the cGPA scores; indicating higher SEI and AMS scores, warrants further exploration of their individual main effects on cGPA.

As regard, model for sGPA including same sets of predictors was significant $(\mathrm{F}(5,214)=12.202, \mathrm{p}<$ $0.001, \mathrm{R}^{2}=0.222$, Adjusted $\left.\mathrm{R}^{2}=0.204\right)$. The results showed that the model predictors have explained $22 \%$ of the variance in sGPA. More specifically, beta coefficients revealed academic progress $(\beta=0.28, \mathrm{p}<0.001)$, SESQ total $(\beta=0.22, \mathrm{p}=0.014$, supporting hypothesis 2$)$ and AMS Total $(\beta=0.17, p=0.024$, supporting hypothesis 2$)$ as unique predictors in semester GPA achievement, whereas age $(\beta=-.01, \mathrm{p}=0.85$, not supporting hypothesis 3 ) and SEI Total ( $\beta=0.02, p=0.76$, not supporting hypothesis 3 ) did not strongly predict semester academic achievement), thus partially supporting the expectation that age and SEI will matter and warranting further exploration of the relationship between sGPA and students' engagement facilitation.

Based on the summary of regression analysis, Figure 2 illustrates the positive and negative predictors of students' performance.

\section{Discussion}

The present study explored learning engagement, motivation and academic achievement among nursing students in a multisite study. Further we examined the state of the relationship between engagement, and motivation and their impact on students' achievement. A number of findings were illuminating. Study findings have implications for research on what always heighten students' academic achievement.
First, the findings of the current study have shown moderate levels of engagement among students with significant variations among the studied campuses. This study focused on three aspects of engagement (behavioural, emotional, and cognitive) as they are highly studied, theoretically distinct student classroom experiences that exemplify the array of educationally essential engagement constructs. Students reported highest levels of school engagement in the benchmarks of: interest in learning, cognitive engagement and affective liking for school. Promoting culture of connectedness with school is therefore at the core of school engagement, particularly emotional engagement. ${ }^{48}$ Reasons for the overall engagement and the higher mean scores for those benchmarks therefore are multifactorial and could possibly be attributed to university-maintained small faculty to student ratio, educational climate encompassing culture of learning and the quality of learning experiences that are provided. This was maintained by Abd El-Maqsood and Taha $(2018)^{49}$ who emphasized that subjects engaged positively because the educational environment offer a diversity of learning opportunities that augment their engagement. Similarly, Reinke (2019) ${ }^{50}$ added that students' perceptions of the classroom environment have been shown to influence their learning behaviors and the learning outcomes. Konold et al (2018) $;^{48}$ Hudson and Carrasco $(2015)^{2}$ reported that school climate that sustain key features of creativity, collaboration, active learning, and integrative thinking are associated with higher student engagement in schools. Consistent with previous literature, Courtner (2014) ${ }^{51}$ further added that student-faculty interaction, supportive campus environment, and enriching educational experiences was the 


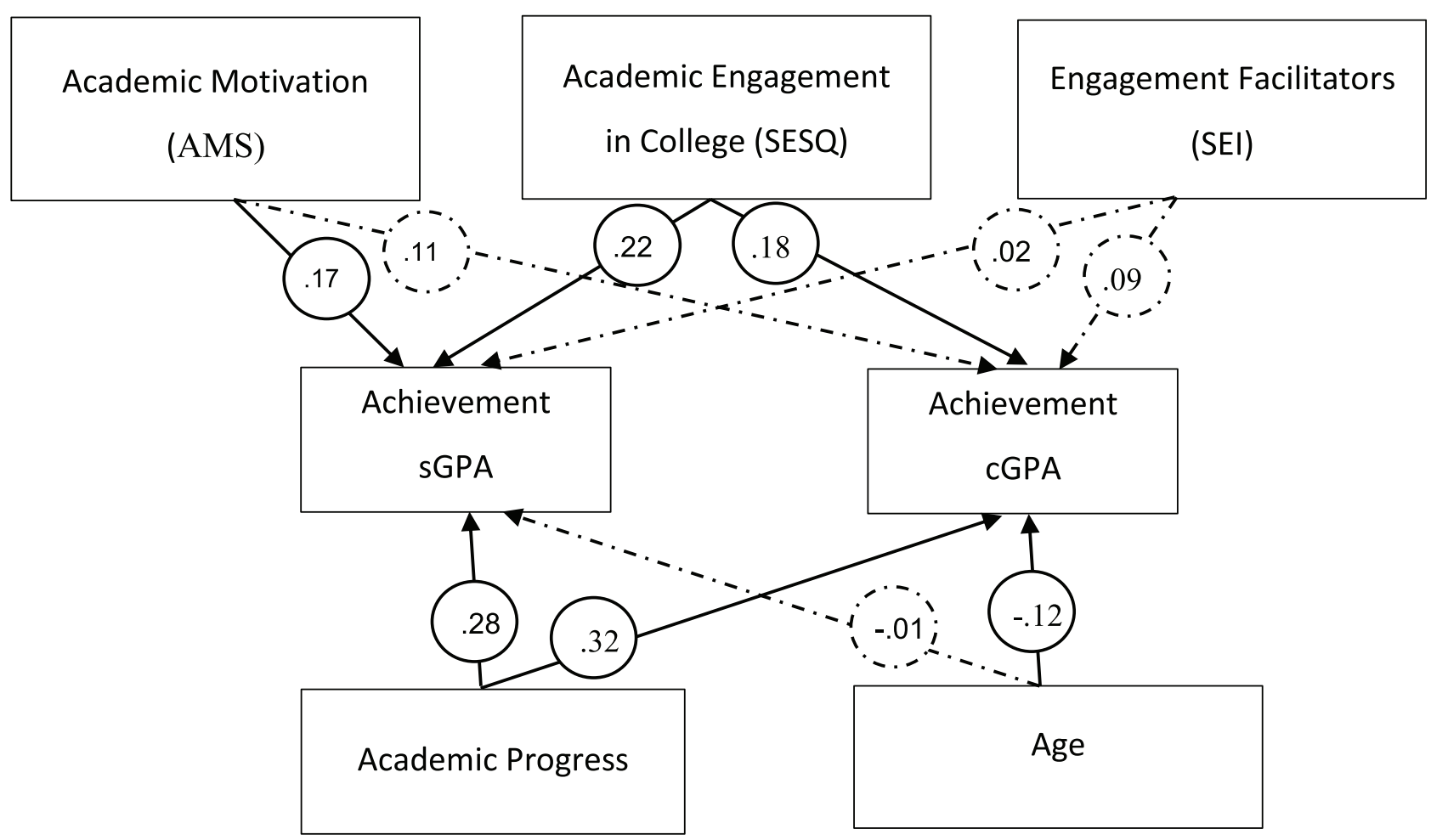

Figure 2 Standardized regression coefficients for the final study model.

highest benchmarks of the student engagement process for traditional students. Despite the fact that the independent role of teacher-student relationship was insufficiently perceived by student as important engagement facilitator, role of teacher in enhancing the teachinglearning environment cannot be ignored.

Second, study found that Riyadh and Alhasa had similarly maintained high level of students' engagement compared to Jeddah campus. This finding could first be explained in light of Jeddah students' lower engagement indicators in areas of perceived behavioral efforts and persistence, behavioral extracurricular as well as affective liking for learning. Ladd and Dinella $(2009)^{52}$ found that students displaying a higher behavioral and affective engagement exhibited higher achievement. Interestingly, study data have further showed significantly lower perception of two main engagement facilitators, which are peer support for learning and relevance of schoolwork which might had influential impact on their overall engagement at school in same campus. The same result has been observed in the study of Hudson and Carrasco (2015) ${ }^{2}$ who reported lower score for students' interactions with peers and this was identified as an area to be focused on future endeavors. It is worth mentioning that students have markedly different roles on school conditions that might influence the overall learning experience and associated outcomes. Literature shows that quality of relationships with peers has an important critical role for peer academic support that can foster students sense of belonging, academic achievement and learning engagement. ${ }^{2,51}$ With regard to students' perceived relevance and control of school work, Wang and Eccles $(2013)^{53}$ reported that greater learning is more common when the curriculum includes meaningful topics that reflect students' personal goals and interests. Wood $(2020)^{54}$ reported that students who viewed themselves as having control over opportunities to show their competencies are more likely to selfreport as engaged. Similarly, Abd El-Maqsood and Taha $(2018)^{49}$ emphasized that the breadth and quality of learning opportunities promotes students' engagement but workload limits their engagement in both classroom and clinical experience. Finally, Schlenker et al (2013), ${ }^{41}$ with 234 American college students, emphasized that engagement is a direct result of perceiving a specific set of priorities and goals and personal control over performance. This emphasizes the fundamental role of school and the 
responsibility of the teachers in ensuring relevance of planned activities so that students' engagement could be enhanced.

Moreover, data have shown that, students have reported high levels of academic motivation scores. Interestingly, this was consistent with students' high rating of future goals and aspirations as the most importantly perceived engagement facilitators. Similar findings were reported by El Nilsson and Stomberg (2008), ${ }^{55}$ and Mäenpää, Järvenoja, Peltonen and Pyhältö (2019). ${ }^{56}$ Mäenpää et al (2019) ${ }^{56}$ attributed their undergraduate nursing students' display of high to moderate levels of motivation regulation to the positive student's perception of school. In fact, institutions have a significant influence on students' motivation through provision of supportive services for achieving desired goals and meeting needs. Many studies highlighted the role of curriculum content and pedagogical practices (e.g., instructional design and teaching strategies) on motivation. El Nilsson and Stomberg's $(2008)^{55}$ study demonstrated that extrinsic motivators, such as teachers' involvement, program organization, study contents relevant to the profession, are more commonly used as explanation to the motivation score than are intrinsic factors such as attitude to the study and study result.

Regarding differences in perceived academic motivation among the three campuses, Alhasa campus showed the highest level in all academic motivation indicators while Jeddah campus was significantly low in the external regulation and introjected regulation compared to others. To explain this, it is important to consider the differences in the sociological factors (social, cultural, and economic) between the three regions. Riyadh and Jeddah both are big cities with large number of population, both are classified as industrial modern cities, and people have relatively high income, ${ }^{57}$ while Alhasa is classified as an agricultural environment and most of the people have a lower financial income. ${ }^{58}$ According to the governmental statistics in Saudi Arabia, the percentage of international scholars from Alhasa region is relatively high specially in vital specialties such as; medicine, technology and petrochemical sciences. ${ }^{59}$ A large number of Alhasa's residents aspire to obtain high education levels for selfdevelopment and for income improvement. Therefore, they tend to be more enthusiastic, motivated, and competitive to prove their merit. This claim is consistent with many studies that proved the importance of learner background characteristics for his/her motivation, academic performance and achievement. ${ }^{60,61}$ It is equally important to consider pedagogical practices factor and learning culture which are distinct features for each campus which have been thought to additionally contribute to the differences found between campuses.

Concerning student achievement, findings revealed satisfactory results in the three campuses. This could be explained by the university unified bachelor program and courses syllabi, and university annual formative progress testing for assessment of students' achievement in the three campuses. Another antecedent explain findings in this study is the institutional support provided with the endless opportunities for students to learn and to develop their competence. It is worth noting that study findings have also shown that students' reported engagement and motivation are linked to their academic achievement as per the findings of the regression analyses. Based on the above, the current study supports other similar previous findings ${ }^{27,30,36,37,39}$ claiming that highly motivated and engaged students are more likely to have higher achievement in their study. Taken together, we should emphasize that it is the combined influence of engagement and motivation together that affected students' achievement than the main effect of motivation alone as demonstrated by the research data. However, in the following section we would discuss main effect of engagement and motivation on achievement for more understanding of the relationships.

Regarding effect of engagement on achievement, examination of standardized coefficients revealed students' cGPA and sGPA can be determined by engagement. The positive relationship between learning engagement and academic achievement, has already been confirmed by $\mathrm{Wu}, \mathrm{Li}$, Zheng and Guo (2020) ${ }^{62}$ on a group of 1930 medical students. This finding is supported by other studies. ${ }^{30,41,48,63-66}$ Al-Bahadli (2020) ${ }^{63}$ study among forty students from the Department of English reported a positive correlation between students' cognitive, affective, and behavioral engagement and their academic achievement. Similarly, Reinke (2019) ${ }^{50}$ found a positive relationship between high academic achievement in physiology and both the number of hours dedicated to private study and total cognitive engagement with learning resources. The following studies believe that school engagement is related to a number of positive academic and personal outcomes. ${ }^{67,68}$ Hudson and Carrasco $(2015)^{2}$ reported that student's level of engagement is extremely vital for their sense of learning and effective progression within the profession. Lee $(2014)^{69}$ verified that student 
engagement at school significantly predicted their academic performance and that effect of emotional engagement on reading performance was partially mediated through behavioral engagement.

Data also showed high correlation between motivation and academic achievement. In addition, the study findings indicated that academic motivation do predict sGPA with no main effect on cGPA. The studies investigating the relationships between academic performance and students' motivation have produced similar results to our study. Mäenpää et al $(2019)^{56}$ found a relationship between an overall high level of motivation regulation and academic performance (GPA). $\mathrm{Wu}$ et al $(2020)^{62}$ results from SEM showed that intrinsic motivation was significantly and positively associated with learning engagement and academic performance while extrinsic motivation was positively related to learning engagement but not with students' academic performance. Reinke (2019) reported that academic self-regulatory skills must be considered when attempting to heighten student levels of involvement and achievement. Therefore, Wu et al $(2020)^{62}$ recommended that motivation-related interventions have a higher probability of enabling higher academic performance.

Another finding is the significant association of motivation with students' engagement. This result is in line with earlier studies, which indicated that highly motivated students can simultaneously demonstrate high engagement. ${ }^{53,62,70}$ Entwistle and Peterson (2004); ${ }^{71}$ Ghasemi, Moonaghi and Heydari (2008) ${ }^{72}$ emphasized the role of learning attitudes and learning motivations, as being crucial student-related factors affecting students' academic engagement in learning process. Wang and Eccles $(2013)^{53}$ revealed that understanding student engagement in school requires consideration of the interaction of the psychological, developmental and contextual factors in their life. Moreover, Martin, Ginns, and Papworth $(2017)^{57}$ suggested a cyclical process controlling the relationship between motivation and engagement, claiming that prior motivation is a drive for subsequent engagement; while prior engagement exerts significant role in predicting subsequent motivation. Similarly, Cazan $(2015)^{73}$ emphasized that students' success in achieving their goals can post their motivation and engagement in learning activities, and that engagement also do determine students' motivation for learning.

Finally, it is not possible to generalize that existence of motivations for learning and presence of learning engagement can always lead to high academic success without considering the differences in background capabilities between students. This claim was supported by study findings of the role of age in predicting students' academic achievement. Among interesting finding is the moderate negative relationship between students' age, engagement and their academic achievement. This implies a positive impact of younger students' age on learning process. This is contrary to the literature declaring that student's maturity level contributes to improve learning experience as students tend to be more responsible about their learning and this makes them become more engaged in their study. ${ }^{60}$ A possible explanation to this would probably be the increased study load and the increased complexity of nursing courses in advanced years of study. Factors such as bearing the academic burden, perseverance in studying, and the mental abilities of students might provide further possible explanation. It is also possible that students' engagement played a role in mediating the relationship between background variables and students' academic achievement as contended by Ribeiro et al (2019). ${ }^{66}$

\section{Limitations}

One of the most important limitations was the use of the students' self-report measures for academic achievement (GPA), engagement and motivation. These might lead to social desirability bias and memory inaccuracies which can influence the data collected. Restrictions imposed a consequence of using a cross-sectional design included the inability to track trends of interacting relationship of student engagement, motivation and achievement over time.

\section{Conclusion}

The present study examined the relationship of nursing students' engagement, motivation for leaning and their academic achievement. This article is significant as there is a lack of knowledge as regards impact of nursing students' engagement levels and motivations on semester and cumulative academic achievement. The study has identified reliable correlates of active engagement and motivation, and highlighted some issues that need improvement in order to promote student learning and achievement. The study findings should be used to assess the potential for curricular development and design adjustments.

Data was collected from three campuses and 425 students with an average age of $21.52 \pm 1.12$ years. Overall, respondents reported moderate levels of engagement in school with significant difference among the three 
campuses. Interest in learning ranked first, followed by cognitive engagement and affective liking for school. Students reported high level for facilitators of engagement. Respondents showed high academic motivation with a score of $4.89 \pm 1.03$. Correlational analysis between the study factors of engagement, motivation, and academic performance indicated medium to large associations. The overall regression equation including variables of age, academic progress, academic engagement, motivation and engagement facilitators significantly explained $24 \%$ of the variance in cGPA and $22 \%$ of the variance in sGPA scores.

One positive conclusion that can be inferred is that engagement and motivation are factors that must be considered when endeavoring to increase student academic performance. The findings of this research show that the creation of a supportive and motivating learning environment is an important factor in promoting student engagement and learning achievement. An educational institution with its faculty and staff need to understand what motivates the students to learn and to actively engage in school activities.

\section{Recommendations}

Because of the multidimensionality of the constructs, it is recommended that future studies use a variety of measures of student engagement for use both by students and faculty to better explore students' engagement situation. Universities have a responsibility to society to make education a successful experience, current study therefore can be a benchmark for achieving that. Findings could be used to determine the levels of engagement of nursing students, and to identify specific areas for improvement in the studied outcomes variables of engagement, motivation and achievement. Moreover, future attempts to determine levels of student engagement could be improved by including teachers' assessment of their students' engagement rather than solely depending on students' selfreports. Lastly, conducting a longitudinal study might be required to study trend in change in the interaction between engagement, motivation and achievement over time.

\section{Disclosure}

The abstract for the study was presented at the 48th Global Nursing \& Healthcare Conference, March 04-06, 2019, Barcelona, Spain.
The authors report no potential conflicts of interest with respect to this work.

\section{References}

1. Crookes K, Crookes PA, Walsh K. Meaningful and engaging teaching techniques for student nurses: a literature review. Nurse Educ Pract. 2013;13:239-243. doi:10.1016/j.nepr.2013.04.008

2. Hudson K, Carrasco R. Researching nursing students' engagement: successful findings for nursing. Int J Nurs Clin Pract. 2015;2:150. doi:10.15344/2394-4978/2015/150

3. Richards J, Sweet L, Billett S. Preparing medical students as agentic learners through enhancing student engagement in clinical education. Asia-Pac J Coop Educ. 2013;14(4):251-263.

4. D'Souza MS, Venkatesaperumal R, Radhakrishnan J, Balachandran S. Engagement in clinical learning environment among nursing students: role of nurse educators. Open J Nurs. 2013;3:25-32. doi:10.4236/ojn.2013.31004

5. Reeve J, Tseng C-M. Agency as a fourth aspect of students' engagement during learning activities. Contemp Educ Psychol. 2011;36 (4):257-267. doi:10.1016/j.cedpsych.2011.05.002

6. Christenson SL, Reschly AL, Wylie C, Eds. The Handbook of Research on Student Engagement. New York: Springer Science; 2012:763-782.

7. Skinner EA, Kindermann TA, Furrer CJ. A motivational perspective on engagement and disaffection: conceptualization and assessment of children's behavioral and emotional participation in academic activities in the classroom. Educ Psychol Meas. 2009;69:493-525. doi:10.1177/0013164408323233

8. Mthimunye KDT, Daniels FM. Exploring the challenges and efforts implemented to improve the academic performance and success of nursing students at a university in the Western Cape. Int $J$ Afri Nurs Sci. 2020;12:100196. doi:10.1016/j.ijans.2020.100196

9. York TT, Gibson C, Rankin S. Defining and measuring academic success. Pract Assess Res Evaluation. 2015;20(5):1-20.

10. Reeve J, Lee W. Students' classroom engagement produces longitudinal changes in classroom motivation. J Educ Psychol. 2014;10 6(2):527-540. doi:10.1037/a0034934

11. Wang MT, Fredricks JA. The reciprocal links between school engagement, youth problem behaviors, and school dropout during adolescence. Child Dev. 2014;85(2):722-737. doi:10.1111/cdev.12138

12. Wara E, Aloka PJ, Odongo BC. Relationship between emotional engagement and academic achievement among Kenyan secondary school students. Acad J Interdiscipl Stud. 2018;7(1):107-118. doi:10.2478/ajis-2018-0011.

13. Hudson KF. Nursing student engagement: student, classroom, and clinical engagement. Int $J$ Nurs. 2015;4(1):44-52.

14. Exetera DJ, Ameratungaa S, Ratimab M, et al. Student engagement in very large classes: the teachers' perspective. Stud High Educ. 2010;35(7):761-775. doi:10.1080/03075070903545058

15. Hu S, Wolniak G. College student engagement and early career earnings: differences by gender, race/ethnicity, and academic preparation. Rev High Educ. 2013;36(2):221-233. doi:10.1353/rhe.2013.0002

16. Hudson K, Carrasco R. Nursing student engagement: taking a closer look. Open J Nurs. 2017;7:193-201. doi:10.4236/ojn.2017.72017

17. Rejnö Å, Nordin P, Forsgren S, Sundell Y, Rudolfsson G. Nursing students' attendance at learning activities in relation to attainment and passing courses: a prospective quantitative study. Nurse Educ Today. 2017;50:36-41. doi:10.1016/j.nedt.2016.11.025

18. Cooper C, Carter N. Problem based learning in mental health nursing: the students' experience. Int J Ment Health Nurs. 2012;21:175-183. doi:10.1111/j.1447-0349.2011.00788.x

19. Fredricks JA, Filsecker M, Lawson MA. Student engagement, context, and adjustment: addressing definitional, measurement, and methodological issues. Learn Instr. 2016;43(3):1-4. doi:10.1016/j. learninstruc.2016.02.002 
20. McFarland J, Cui J, Rathbun A, Holmes J. Trends in high school dropout and completion rates in the United States: 2018. Compendium Report. (NCES 2019-117). Washington, DC: National Center for Education Statistics, Institute of Education Sciences, U.S. Department of Education; 2018. Available from: http://nces.ed.gov/ pubsearch. Accessed November 11, 2020.

21. Li Y, Lerner RM. Interrelations of behavioral, emotional, and cognitive school engagement in high school students. $J$ Youth Adolesc. 2013;42(1):20-32. doi:10.1007/s10964-012-9857-5.

22. Dotterer AM, Lowe K. Classroom context, school engagement, and academic achievement in early adolescence. $J$ Youth Adolesc. 2011;40(12):1649-1660. doi:10.1007/s10964-011-9647-5

23. Casuso-Holgado MJ, Cuesta-Vargas AI, Moreno-Morales N, Labajos-Manzanares MT, Barón-López FJ, Vega-Cuesta M. The association between academic engagement and achievement in health sciences students. BMC Med Educ. 2013;13:33. doi:10.1186/14726920-13-33

24. Abdul Sattar A, Kouar R, Gillani AA. Exploring nursing students engagement in their learning environment. Am J Nurs Res. 2018;6 (1):18-23. doi:10.12691/ajnr-6-1-3.

25. Ghiyasvandian S, Shahsavari H, Kazemnejad A, Goodarzi Z, Razavi SN. The relationship between classroom management style with engagement and academic achievement. Iran J Nurs Res. 2019;14(2). doi:10.21859/ijnr-140209

26. Abid N, Akhtar M. Relationship between academic engagement and academic achievement: an empirical evidence of secondary school students. J Educ Res. 2020;23(1):48-61.

27. Leong CSU, Clutter LB. Active learning improves nursing student clinical performance in an academic institution in Macao. Chin Nurs Res. 2015;2:35-39. doi:10.1016/j.cnre.2015.08.001

28. Maenpaa K, Pyhalto K, Jarvenoja H, Peltonen J. Nursing students' motivation regulation and its relationship with engagement and burnout. Nordic JNurs Res. 2018;38(3):143-150. doi:10.1177/2057158517731719

29. Raines DA. An innovation to facilitate student engagement and learning: crossword puzzles in the classroom. Teach Learn Nurs. 2010;5:85-90. doi:10.1016/j.teln.2008.08.003

30. Oga-Baldwin WLQ, Nakata Y. Engagement, gender, and motivation: a predictive model for Japanese young language learners. System. 2017;65:151-163. doi:10.1016/j.system.2017.01.011

31. Sturges D, Maurer TW, Allen D, Gatch DB, Shankar P. Academic performance in human anatomy and physiology classes: a 2-yr study of academic motivation and grade expectation. Adv Physiol Educ. 2016;40:26-31. doi:10.1152/advan.00091.2015

32. Sharififard F, Asayesh H, Hosseini MHM, Sepahvandi M. Motivation, self-efficacy, stress, and academic performance correlation with academic burnout among nursing students. J Nurs Midwifery Sci. 2020;7:88-93. doi:10.4103/JNMS.JNMS_30_19

33. Rose S. Academic success of nursing students: does motivation matter? Teach Learn Nurs. 2011;6:181-184. doi:10.1016/j.teln.2011. 05.004

34. Loftin C, Davis LA, Hartin V. Classroom participation: a student perspective. Teach Learn Nurs. 2010;5:119-124. doi:10.1016/j.teln. 2010.02.004

35. Lepper M, Corpus J, Iyengar S. Intrinsic and extrinsic motivational orientations in the classroom: age differences and academic correlates. J Educ Psychol. 2005;97(2):184-196. doi:10.1037/00220663.97.2.184

36. Bowcock R, Peters K. Discussion paper: conceptual comparison of student and therapeutic engagement. Nurse Educ Pract. 2016; 17:188-191. doi:10.1016/j.nepr.2015.10.010

37. Salamonson Y, Andrew S, Clauson J, Jacobs S, Cleary M, Jackson D. Linguistic diversity as sociodemographic predictor of nursing program progression and completion. Contemp Nurse. 2011;38 (1e2):84-93. doi:10.5172/conu.2011.38.1-2.84
38. Jeffreys MR. Tracking students through program entry, progression, graduation, and licensure: assessing undergraduate nursing student retention and success. Nurse Educ Today. 2007;27(5):406-419. doi:10.1016/j.nedt.2006.07.003

39. Korvick LM, Wisener LK, Loftis LA, Williamson ML. Comparing the academic performance of students in traditional and second-degree baccalaureate programs. J Nurs Educ. 2008;47 (3):139-141. doi:10.3928/01484834-20080301-10

40. Kahu E, Nelson K, Picton C. Student interest as a key driver of engagement for first year students. Stud Success. 2017;8(2):55-66. doi:10.5204/ssj.v8i2.379

41. Schlenker BR, Schlenker PA, Schlenker KA. Antecedents of academic engagement and the implications for college grades. Learn Individ Differ. 2013;27:75-81. doi:10.1016/j.lindif.2013. 06.014

42. Galugu NS, Riko S. Academic self-concept, teacher's supports and student's engagement in the school. Jurnal Psikologi Pendidikan Konseling. 2019;5(2):141-147. doi:10.26858/jppk.v5i2.10549

43. Lam SF, Jimerson SR. Exploring Student Engagement in Schools Internationally: Consultation Paper. Chicago, IL: International School Psychologist Association; 2008.

44. Appleton JJ, Christenson SL, Kim D, Reschly AL. Measuring cognitive and psychological engagement: validation of the student engagement instrument. $J$ Sch Psychol. 2006;44:427-445. doi:10.10 16/j.jsp.2006.04.002

45. Vallerand RJ, Pelletier LG, Blais MR, Brière NM, Senécal C, Vallières EF. The academic motivation scale: a measure of intrinsic, extrinsic, and amotivation in education. Educ Psychol Meas. 1992;52:1003-1019. doi:10.1177/0013164492052004025

46. Alivernini F, Lucidi F. The Academic Motivation Scale (AMS): factorial structure, invariance, and validity in the Italian context. TPM. 2008;15(4):211-220.

47. Haslofçala F, Korkmaz NH, Çalişkan H, Önder I, Masal E, Beşoluk Ş. Reliability and validity of academic motivation scale for sports high school students. SHS Web Conf. 2016;26:01104. doi:10.1051/shsconf/20162601104

48. Konold T, Cornell D, Jia Y, Malone M. School climate, student engagement, and academic achievement: a latent variable, multilevel multi-informant examination. AERA Open. 2018;4(4):1-17. doi:10.11 77/2332858418815661

49. Abd El-Maqsood AS, Taha EE. Nursing students' engagement in the learning environment. IOSR J Nurs Health Sci. 2018;7(6):47-53.

50. Reinke NB. Promoting student engagement and academic achievement in first-year anatomy and physiology courses. Adv Physiol Educ. 2019;43:443-450. doi:10.1152/advan.00205.2018

51. Courtner A. Impact of student engagement on academic performance and quality of relationships of traditional and nontraditional students. Int J Educ. 2014;6(2):24-45. doi:10.5296/ije.v6i2.5316

52. Ladd GW, Dinella LM. Continuity and change in early school engagement: predictive of children's achievement trajectories from first to eighth grade? J Educ Psychol. 2009;101(1):190-206. doi:10.1037/a0013153

53. Wang MT, Eccles JS. School context, achievement motivation, and academic engagement: a longitudinal study of school engagement using a multidimensional perspective. Learn Instr. 2013;28:12-23. doi:10.1016/j.learninstruc.2013.04.002

54. Wood R. Investigating the enhancement of students' engagement with learning activities through the lens of Self-Determination Theory. Eur J Teach Educ. 2020;2(2):152-182. doi:10.33422/ejte. v2i2.263

55. El Nilsson K, Stomberg MIW. Nursing students motivation toward their studies - a survey study. BMC Nurs. 2008;7:6. doi:10.1186/ 1472-6955-7-6 
56. Mäenpää K, Järvenoja H, Peltonen J, Pyhältö K. Progress of nursing students' motivation regulation profiles and affiliations with engagement, burnout and academic performance. Int J Teach Learn High Educ. 2019;31(3):461-475.

57. Salam AA, Elsegaey I, Khraif R, Al-Mutairi A. Population distribution and household conditions in Saudi Arabia: reflections from the 2010 Census. Springerplus. 2014;3(1):530. doi:10.1186/2193-18013-530

58. Al-Khraif R, Salam A, Abdul-Rashid MF. Family demographic transition in Saudi Arabia: emerging issues and concerns. Sage Open. 2020;10(1):1-13. doi:10.1177/2158244020914556

59. Fawzy B, Brian D. Student scholarships in Saudi Arabia: implications and opportunities for overseas engagement. Semantic Scholar. 2013;12:152-153.

60. Omondi B. The relationship between learner characteristics and academic performance of distance learners: the case of external degree programme of the University of Nairobi. J Cont Open Distance Educ. 2011;1(2):9-107.

61. Wilfred WL, Allan HY. Modelling programming performance: beyond the influence of learner characteristics. Comput Educ. 2011;57(1):1202-1213. doi:10.1016/j.compedu.2011.01.002

62. Wu H, Li S, Zheng J, Guo J. Medical students' motivation and academic performance: the mediating roles of self-efficacy and learning engagement. Med Educ Online. 2020;25:1742964. doi:10.1080/ 10872981.2020.1742964

63. Al-Bahadli HK. The correlation between Iraqi college students' engagement and their academic achievement. Int J Res Soc Sci Human. 2020;10(2):247-257. doi:10.37648/ijrssh.v10i02.021

64. Fung F, Tan CY, Chen G. Student engagement and mathematics achievement: unraveling main and interactive effects. Psychol Sch. 2018;1-18. doi:10.1002/pits.22139
65. Paulo M, Paulo D, Filipa MV, Machado V. Predictors of academic performance and school engagement - integrating persistence, motivation and study skills perspectives using person-centered and variable-centered approaches. Learn Individ Differ. 2013;11(3):117-125.

66. Ribeiro L, Rosário P, Núñez JC, Gaeta M, Fuentes S. First-year students background and academic achievement: the mediating role of student engagement. Front Psychol. 2019;10:2669. doi:10.3389/ fpsyg.2019.02669

67. James RL, Carol AL. The influence of classroom engagement on community college student learning: a quantitative analysis of effective faculty practices. SAGE J. 2019;47(2):11-53.

68. Kristen CW, Hal AL. Teachers' agency, efficacy, engagement, and emotional resilience during policy innovation implementation. J Educ Change. 2018;19:181-204. doi:10.1007/s10833-017-9313-0

69. Lee JS. The relationship between student engagement and academic performance: is it a myth or reality? J Educ Res. 2014;107 (3):177-185. doi:10.1080/00220671.2013.807491

70. Cazan AM. Learning motivation, engagement and burnout among university students. Procedia Soc Behav Sci. 2015;187:413-417. doi:10.1016/j.sbspro.2015.03.077

71. Entwistle NJ, Peterson ER. Conceptions of learning and knowledge in higher education: relationships with study behavior and influences of learning environments. Int $J$ Educ Res. 2004;41:407-428. doi:10.1016/j.ijer.2005.08.009

72. Ghasemi MR, Moonaghi HK, Heydari A. Student-related factors affecting academic engagement: a qualitative study exploring the experiences of Iranian undergraduate nursing students. Electron Physician. 2008;10(7):7078-7085. doi:10.19082/7078

73. Martin AJ, Ginns P, Papworth B. Motivation and engagement: same or different? Does it matter? Learn Individ Differ. 2017;55:150-162. doi:10.1016/j.lindif.2017.03.013
Advances in Medical Education and Practice

\section{Publish your work in this journal}

Advances in Medical Education and Practice is an international, peerreviewed, open access journal that aims to present and publish research on Medical Education covering medical, dental, nursing and allied health care professional education. The journal covers undergraduate education, postgraduate training and continuing medical education
Dovepress

including emerging trends and innovative models linking education, research, and health care services. The manuscript management system is completely online and includes a very quick and fair peer-review system. Visit http://www.dovepress.com/testimonials.php to read real quotes from published authors. 